\title{
Effect of fibrinolysis on bleeding phenotype in moderate and severe von Willebrand disease
}

Citation for published version (APA):

Willebrand in the Netherlands Study (WiN study) Group, \& Granzen, B. (2012). Effect of fibrinolysis on bleeding phenotype in moderate and severe von Willebrand disease. Haemophilia, 18(3), 444-451. https://doi.org/10.1111/j.1365-2516.2011.02645.x

Document status and date:

Published: 01/05/2012

DOI:

10.1111/j.1365-2516.2011.02645.x

Document Version:

Publisher's PDF, also known as Version of record

\section{Document license:}

Taverne

\section{Please check the document version of this publication:}

- A submitted manuscript is the version of the article upon submission and before peer-review. There can be important differences between the submitted version and the official published version of record.

People interested in the research are advised to contact the author for the final version of the publication, or visit the DOI to the publisher's website.

- The final author version and the galley proof are versions of the publication after peer review.

- The final published version features the final layout of the paper including the volume, issue and page numbers.

Link to publication

\footnotetext{
General rights Owners
rights.

- You may freely distribute the URL identifying the publication in the public portal. please follow below link for the End User Agreement:

www.umlib.nl/taverne-license

Take down policy

If you believe that this document breaches copyright please contact us at:

repository@maastrichtuniversity.nl

providing details and we will investigate your claim.
}

Copyright and moral rights for the publications made accessible in the public portal are retained by the authors and/or other copyright owners and it is a condition of accessing publications that users recognise and abide by the legal requirements associated with these

- Users may download and print one copy of any publication from the public portal for the purpose of private study or research.

- You may not further distribute the material or use it for any profit-making activity or commercial gain

If the publication is distributed under the terms of Article $25 \mathrm{fa}$ of the Dutch Copyright Act, indicated by the "Taverne" license above, 


\title{
Effect of fibrinolysis on bleeding phenotype in moderate and severe von Willebrand disease
}

\author{
E. M. DE WEE, * K. KLAIJ, * H. C. J. EIKENBOOM,†‡J. G. VAN DER BOM, $\$ \mathbb{S}$ K. FIJNVANDRAAT, \\ B. A. P. LAROS-VAN GORKOM,**E. P. MAUSER-BUNSCHOTEN, $\dagger \dagger$ K. MEIJER, $+\ddagger$ \\ G. GOVERDE, $\mathbb{S}$ P. W. G. VAN DER LINDEN, ? D. C. RIJKEN* and F. W. G. LEEBEEK* \\ FOR THE WIN STUDY GROUP \\ *Hematology, Erasmus University Medical Center, Rotterdam, The Netherlands; $\dagger$ Department of Thrombosis and Hemostasis, \\ Leiden University Medical Center, The Netherlands; $\$$ Einthoven Laboratory for Experimental Vascular Medicine, Leiden \\ University Medical Center, The Netherlands; \$Department of Clinical Epidemiology, Leiden University Medical Center, \\ The Netherlands; Pediatric Hematology, Emma Children's Hospital AMC, Amsterdam, The Netherlands; **Hematology, \\ Radboud University Nijmegen Medical Centre, Nijmegen, The Netherlands; ††Van Creveldkliniek and Hematology, \\ University Medical Center Utrecht, The Netherlands; \$Hematology, University Medical Center Groningen, The Netherlands; \\ \$SDepartment of Internal Medicine, Amphia Hospital, Breda, The Netherlands; and Department of Internal Medicine, \\ Kennemer Gasthuis, Haarlem, The Netherlands
}

Summary. Patients with von Willebrand disease (VWD), the most common inherited bleeding disorder, display large variation in bleeding tendency, which is not completely related to VWF levels. The cause of variability in clinical expression is largely unknown. The effect of plasma fibrinolytic capacity on bleeding tendency in VWD patients has not been investigated. We hypothesized that enhanced fibrinolysis may result in a more severe bleeding phenotype. Therefore, we measured the fibrinolytic potential in patients with moderate or severe VWD to investigate the contribution of fibrinolysis to the bleeding tendency. Fibrinolytic potential was measured as plasma clot lysis time (CLT) with and without addition of potato carboxypeptidase inhibitor (PCI) in 638 patients with moderate or severe VWD who participated in a nationwide multicentre cross-sectional study.
Bleeding severity was measured using the Bleeding Score (BS).The CLTs were significantly longer, indicative of hypofibrinolysis, in men compared to women with VWD [106.2 (IQR 95.7-118.1) vs. 101.9 (IQR 92.8-114.0) min]. The CLTs prolonged with increasing age. No association was found between VWF or FVIII levels and CLT, or between VWF or FVIII levels and CLT ${ }^{+P C I}$. No association was observed for BS in a model with $10 \log$ transformed CLT, adjusted for age, gender, VWF:Act and FVIII $[b=6.5(95 \% \mathrm{CI}-0.3$ to 13.4$)]$. Our study showed that the plasma fibrinolytic potential does not influence bleeding tendency in VWD patients and therefore does not explain the variability in bleeding phenotype in VWD.

Keywords: bleeding, fibrinolysis, von Willebrand disease

\section{Introduction}

von Willebrand disease (VWD) is the most common inherited bleeding disorder, caused by defects in or reduced levels of von Willebrand factor (VWF) [1]. The VWF plays a major role in primary haemostasis by

Correspondence: Prof Frank W.G. Leebeek, MD PhD, Erasmus University Medical Center, PO Box 2040, 3000 CA Rotterdam, The Netherlands.

Tel.: +31 10 7034935; fax: +31 107035814 ;

e-mail: f.leebeek@erasmusmc.nl

Accepted after revision 6 August 2011 facilitating adhesion of platelets to the endothelium, thereby initiating aggregation of platelets to form a platelet plug. In addition, VWF is the carrier protein of factor VIII (FVIII) [2].

In patients with VWD, VWF and FVIII levels largely determine the bleeding tendency, however, the variation in bleeding tendency between individuals with VWD is not completely related to VWF levels [3]. Some patients bleed excessively, whereas others with similar VWF levels in plasma have only mild bleeding problems. Also within families with similar mutations, large differences in bleeding phenotype are observed [3]. The cause of this variability in clinical expression of VWD is largely 
unknown. It has recently been shown that variability in thrombin generation may lead to differences in bleeding phenotype in VWD [4].

Another factor that may determine the variability in clinical expression of VWD is the rate of fibrinolysis. The effect of fibrinolysis on the bleeding tendency in VWD patients has not yet been investigated. The fibrinolytic system converts plasminogen into plasmin, which degrades the insoluble fibrin clot into soluble fibrin degradation products. Thrombin activatable fibrinolysis inhibitor (TAFI) connects the coagulation cascade with the fibrinolytic system. Upon high concentrations of thrombin, TAFI is activated by thrombin and effectively inhibits fibrinolysis by removing carboxyterminal lysine residues from partially degraded fibrin, thereby diminishing the cofactor function of fibrin in plasminogen activation [5].

Recent studies have indicated that the fibrinolytic potential, measured by a clot lysis assay, show considerable inter-individual variation [6]. This variability may also influence the bleeding phenotype of VWD individuals. In addition, in severe VWD patients the fibrinolytic potential may be altered by strongly reduced FVIII levels, leading to impaired thrombin generation via the intrinsic feedback-loop and less TAFI activation. Therefore, reduced FVIII levels in VWD not only have an effect on coagulation but may also enhance fibrinolysis. Previous studies have already indicated that TAFI levels and activation correlate with the fibrinolytic potential in healthy individuals $[7,8]$. Patients with enhanced fibrinolysis predominantly present with mucocutaneous bleeding [9-11], such as menorrhagia, epistaxis and gum bleeding. These bleeding symptoms are also frequently observed in patients with VWD [12].

We hypothesized that differences in fibrinolytic capacity may influence the bleeding tendency among VWD patients, i.e. enhanced fibrinolysis may result in a more severe bleeding phenotype. Therefore, we measured the fibrinolytic potential in a large cohort of patients with moderate or severe VWD to investigate the role of fibrinolysis in bleeding phenotype of VWD patients.

\section{Methods}

\section{Willebrand in the Netherlands study}

We performed a nation-wide cross-sectional study among patients with moderate and severe VWD in the Netherlands, the 'Willebrand in the Netherlands' (WiN) study. Patients were recruited at all 13 Haemophilia Treatment Centres in the Netherlands.

We included patients diagnosed with type 1 , type 2 and type 3 VWD who fulfilled both of the following inclusion criteria: (i) haemorrhagic symptoms or a family history of VWD; (ii) historically lowest levels of VWF antigen (VWF:Ag) $\leq 30 \mathrm{U} \mathrm{dL}^{-1}$ and/or VWF activity (VWF ristocetin cofactor activity (VWF:RCo) $\leq 30 \mathrm{U} \mathrm{dL}^{-1}$ and/or factor (F)VIII:C $\leq 40 \mathrm{U} \mathrm{dL}^{-1}$, determined at the local Haemophilia Treatment Centre.

For the current analysis we included all patients, both children and adults. Data were obtained between October 2007 and October 2009. All participants, or their parents, completed a questionnaire and a blood sample was obtained. The Medical Ethical Committee decided that in children blood could only be obtained if for clinical purposes a blood sample was needed. The Medical Ethical Committees at all participating centres approved this study, and written informed consent was obtained from all study participants and/or their parents.

\section{Definitions}

Determination of type of VWD was based on the current ISTH guidelines [13,14], using the laboratory parameters determined at the local Hemophilia Treatment Center. The severity of VWD was defined as proposed by Federici [15]. Severe VWD was defined as the presence of at least one of the following laboratory abnormalities: VWF:Ag $<10 \mathrm{U} \mathrm{dL}^{-1}$, and/or VWF: $\mathrm{CB}<10 \mathrm{U} \mathrm{dL}^{-1}$, and/ or VWF:RCo $<10 \mathrm{U} \mathrm{dL}^{-1}$, and/or FVIII $<20 \mathrm{U} \mathrm{dL}^{-1}$. Moderate VWD was defined as VWF:Ag 10-30 $\mathrm{U} \mathrm{dL}^{-1}$, and/or VWF:CB 10-30 U dL ${ }^{-1}$, and/or VWF:RCo 10$30 \mathrm{U} \mathrm{dL}^{-1}$, and/or FVIII $20-40 \mathrm{U} \mathrm{dL}^{-1}$ [15]. Children were defined as study participants aged $0-16$ years.

\section{Laboratory measurements in VWD}

Historic measured VWF and FVIII levels in the Hemophilia Treatment Centers were used as inclusion criteria for the WiN study, and patients with at least one measurement of VWF below $30 \mathrm{U} \mathrm{dL}^{-1}$ or FVIII below $40 \mathrm{U} \mathrm{dL}^{-1}$ (for type $2 \mathrm{~N}$ ), respectively, were included. All participants were asked to give blood for re-evaluation of von Willebrand parameters.

Peripheral venous blood was collected in tubes containing $3.2 \%(0.109 \mathrm{M})$ sodium citrate. Subsequently, the tubes were centrifuged twice at $2200 \times g$ for $10 \mathrm{~min}$ at room temperature and finally the citrated platelet-poor plasma (PPP) was aliquoted and stored at $-80^{\circ} \mathrm{C}$.

Plasma levels of VWF:Ag, VWF collagen binding (VWF:CB), VWF activity (VWF:Act) and FVIII were measured centrally (Erasmus University Medical Center, Rotterdam, The Netherlands). Briefly, VWF:Ag level was measured with an in-house ELISA using a polyclonal rabbit anti-human VWF antibody (DakoCytomation, Glostrup, Denmark) for capturing and HRP-conjugated anti-human VWF antibody (DakoCytomation) for detecting. The VWF:CB level was measured with an in-house ELISA using collagen type 1 for capturing and HRP-conjugated anti-human VWF 
antibody for detecting. The VWF:Act assay uses latex particles coated with a monoclonal murine antibody directed against the GpIb $\alpha$-binding domain of VWF. These latex particles were incubated with the patient plasma (Instrumentation Laboratory B.V, Breda, The Netherlands) and agglutination of the particles, proportionally to the GpIb $\alpha$-binding activity of VWF, was measured (Sysmex CA-1500, TOA Medical Electronics, Kobe, Japan). The FVIII:C was measured in a one-stage clotting assay (TriniCLOT, Biomerieux, Marcy l'Etoile, France) with FVIII-deficient plasma (Biopool, Umea, Sweden).

\section{Plasma fibrinolytic potential}

The fibrinolytic potential of VWD patients was studied using a plasma fibrinolytic potential assay $[7,16,17]$. Lysis of a tissue factor-induced clot by exogeneous tissue-type plasminogen activator ( $\mathrm{t}-\mathrm{PA}$ ) was studied by monitoring changes in turbidity during clot formation and subsequent lysis as described previously [7]. Briefly, $70 \mu \mathrm{L}$ of citrated PPP was added to 96 wells plate (Falcon; BD Biosciences, Franklin Lakes, NJ, USA) followed by $49 \mu \mathrm{L}$ of assay buffer $(25 \mathrm{~mm}$ HEPES; $137 \mathrm{~mm} \mathrm{NaCl} ; 3.5 \mathrm{~mm} \mathrm{KCl} ; 1 \%$ BSA; pH 7.4). After mixing, $85 \mu \mathrm{L}$ of the diluted plasma was added to another 96 wells plate containing $15 \mu \mathrm{L}$ assay mixture. The assay mixture included: assay buffer, tissue factor (Innovin, Dade Behring, Marburg, Germany), $\mathrm{CaCl}_{2}$, t-PA (Actilyse, Boehringer Ingelheim, Ingelheim am Rhein, Germany), phospholipids (Rossix, Mölndal, Sweden). Plasma samples were measured both in absence and presence of potato carboxypeptidase inhibitor (PCI), a potent inhibitor of activated TAFI [18]. The inhibitory effect of TAFI on the fibrinolytic potential is excluded by adding PCI. The final concentrations in the plasma clot were $1000 \times$ diluted tissue factor (Innovin), $17 \mathrm{~mm} \mathrm{CaCl}_{2}$, $30 \mathrm{ng} \mathrm{mL}^{-1} \mathrm{t}$-PA, $10 \mu \mathrm{m}$ phospholipids and $2 \times$ diluted plasma. In the measurements with PCI, the final concentration of PCI in the plasma clot was $30 \mu \mathrm{g} \mathrm{mL}{ }^{-1}$. Finally, after mixing the diluted plasma with the assay mixture (1400 rpm on a plate shaker for $10 \mathrm{~s}$ ), $50 \mu \mathrm{L}$ paraffin oil (Merck, Darmstadt, Germany) was added to the wells. The plate was then immediately inserted into a $37^{\circ} \mathrm{C}$ preheated microplate reader (Biotek, Winooski, VT, USA). Optical density was measured at $405 \mathrm{~nm}$ every minute for $300 \mathrm{~min}$. The time of the midpoint from the lowest to highest optical density was used as a measure for clotting time, while the time of the midpoint from highest to lowest optical density was used as a measure for lysis time. The clot lysis time (CLT) was calculated as the difference between clotting and lysis time. A representative graph of the fibrinolytic potential assay (optical density plotted against time) is shown in Fig. 1 . The intra- and inter-assay variation coefficients were $3.5 \%$ and $6.5 \%$, respectively.

In patients with type $3 \mathrm{VWD}$, low FVIII levels due to an increased FVIII clearance, will theoretically lead to less thrombin generation and subsequently to less TAFI activation and more enhancement of fibrinolysis (shortened CLT). Clot lysis time ratio (CLT ratio) was defined as CLT divided by CLT $^{+\mathrm{PCI}}$, thus CLT with TAFI activity divided by CLT without TAFI activity. The CLT ratio was measured to study the effect of TAFI per type of VWD.

\section{Bleeding severity}

Bleeding severity was assessed using the Tosetto Bleeding Score (BS) $[3,19]$. The BS systematically evaluates bleeding symptoms, and accounts for both the number and severity of the bleeding symptoms. The 12 bleeding items are scored on a scale ranging from -1 to 4 points. Higher scores reflect more severe/frequent bleeding. The total for all 12 items results in a BS that can range from -3 (no bleeding) to 45 (severe bleeding).

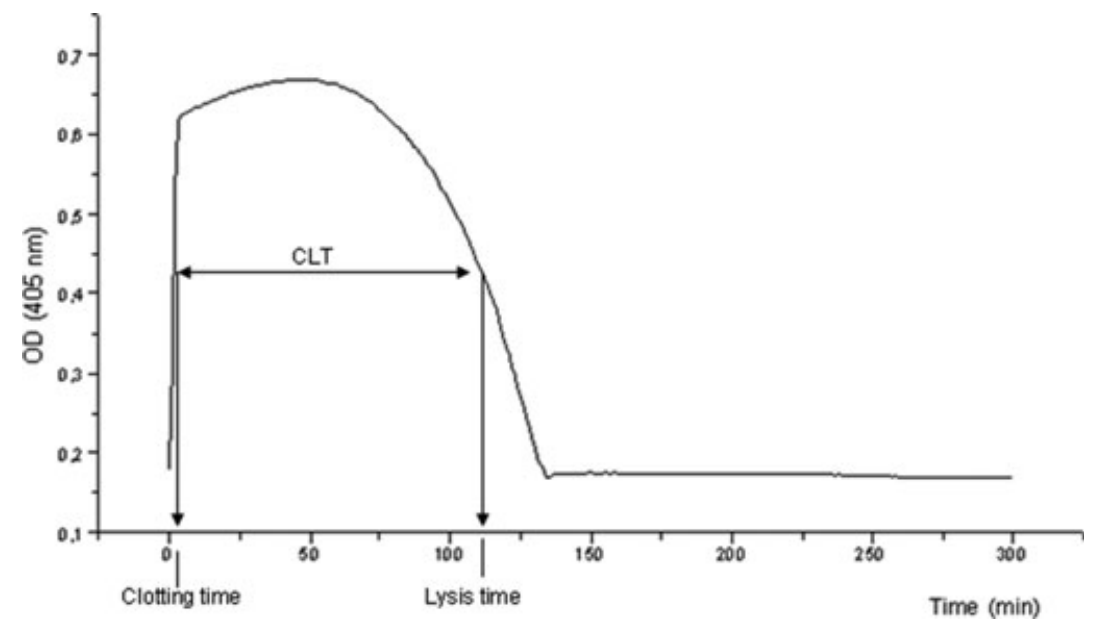

Fig. 1. A representative graph of the output generated by the plasma fibrinolytic potential assay. Clot lysis time (CLT) was calculated as the difference between clotting and lysis time. 
For additional analysis, we also used a mucocutaneous bleeding score (BS-mucocutaneous), which accounts for six mucocutaneous bleeding symptoms (epistaxis, bleeding from minor wounds, oral cavity bleeding, gastrointestinal bleeding, bleeding after tooth extraction and menorrhagia).

\section{Statistical analysis}

Data were analysed with two objectives. First, determinants of CLT were assessed. The CLT presented a skewed distribution to the right. Due to non-normal distribution, the Mann-Whitney $U$ and Kruskal-Wallis tests were used to compare CLT between groups. We used linear regression to model the associations between CLT and its potential determinants. Because the distribution of CLT is skewed, CLT was 10log-transformed. Second, we investigated the association between CLT and BS. Three linear regression models were built with BS or BS-mucocutaneous as dependent variable and 10log-CLT, age, gender, FVIII and VWF:Act as the predictor variables. A $P$-value of $\leq 0.05$ was considered statistically significant.

\section{Results}

\section{Population WiN study}

In the Willebrand in the Netherlands (WiN) study, 806 patients with moderate to severe VWD were included. Plasma was available for 687 VWD patients. Eighteen VWD patients were excluded because of either pregnancy or treatment with desmopressin or FVIII/VWF concentrate 3 days before blood samples were drawn. In 31 VWD patients, no CLT could be determined as the plasma clot did not reach the midpoint from maximum turbidity to clear transition within $300 \mathrm{~min}$. These patients were excluded from subsequent analyses. A flow chart of the study population is shown in Fig. 2.

Table 1 shows the characteristics of the WiN study population. In total, for 638 patients both data on bleeding phenotype and CLT were available; of these $61 \%$ were women. The majority of patients were diagnosed as VWD type $1(n=372,58 \%)$, type 2 was diagnosed in $35 \%(n=222)$, type 3 was diagnosed in $4 \%(n=28)$ of the included patients, and 3\% $(n=16)$ of the patients remained non-classified. VWF:Ag, VWF:CB, VWF:Act and FVIII levels were strongly reduced in our cohort with VWD patients, see Table 1. Median CLT of the study population was $102.5 \mathrm{~min}$ [inter-quartile range (IQR) 92.3-114.0 min], median $\mathrm{CLT}^{+\mathrm{PCI}}$ was $72.1 \mathrm{~min}$ (IQR 65.4-80.9 $\mathrm{min}$ ).

An association between VWF or FVIII level and BS was found. The median BS was 11 (95\% CI 10-11) in $(n=564)$ patients with VWF:Ag levels $>10 \mathrm{IU} \mathrm{dL}^{-1}$ and $15(13-17)$ in $(n=74)$ patients with VWF:Ag level

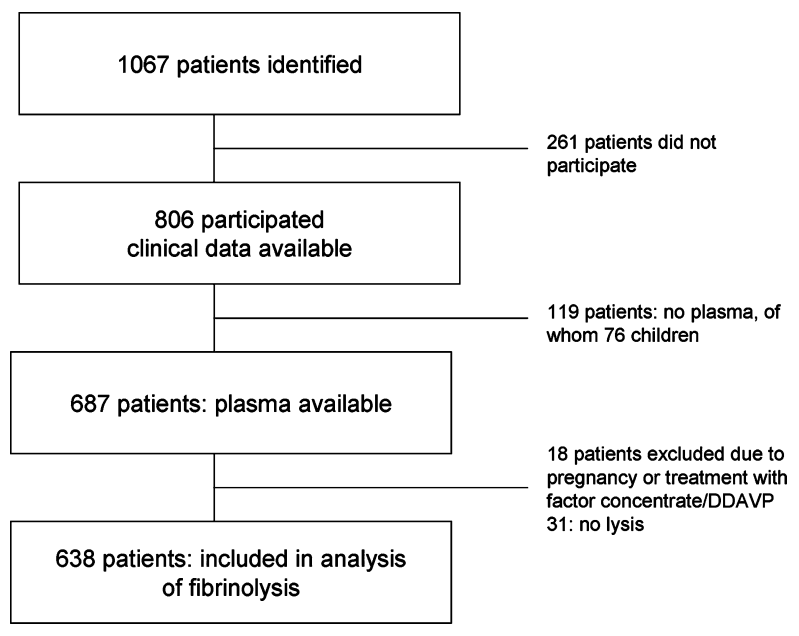

Fig. 2. Flow chart of the WiN study population.

Table 1. Characteristics of the WiN study population.

\begin{tabular}{llrc}
\hline Total $n=638$ & & \\
\hline Gender & Females $(n, \%)$ & 389 & $61 \%$ \\
Age & Median, IQR & 45 & $30-58$ \\
VWD type & $1(n, \%)$ & 372 & $58 \%$ \\
& $2(n, \%)$ & 222 & $35 \%$ \\
& $2 \mathrm{~A}$ & 92 & \\
& $2 \mathrm{~B}$ & 57 & \\
& 2M & 30 & \\
& 2N & 15 & \\
& 2 not specified & 28 & \\
& $3(n, \%)$ & 28 & $4 \%$ \\
VWF:Ag & Unspecified $(n, \%)$ & 16 & $3 \%$ \\
VWF:CB & Median U dL ${ }^{-1}$, IQR & 29 & $18-44$ \\
VWF:Act & Median U dL ${ }^{-1}, \mathrm{IQR}$ & 22 & $7-49$ \\
FVIII:C & Median U dL ${ }^{-1}, \mathrm{IQR}$ & 22 & $8-52$ \\
Blood group O & Median U dL ${ }^{-1}, \mathrm{IQR}$ & 50 & $32-72$ \\
VWD severity & $n$, $\%$ & 382 & $60 \%$ \\
& Severe VWD $(n, \%)$ & 253 & $40 \%$ \\
Bleeding Score & Moderate VWD $(n, \%)$ & 385 & $60 \%$ \\
CLT & Median, range & 10 & $-1-35$ \\
CLT ${ }^{+P C I}$ & Median (min), IQR & 102.5 & $92.3-114.0$ \\
\hline
\end{tabular}

IQR, interquartile range; PCI, potato carboxypeptidase inhibitor; VWD, von Willebrand disease; VWF, von Willebrand factor; CLT, clot lysis time.

$\leq 10 \mathrm{IU} \mathrm{dL}^{-1}$. Patients with VWF:Act levels $>10 \mathrm{IU} \mathrm{dL}^{-1}$ $(n=473)$ or FVIII:C levels $>10 \mathrm{IU} \mathrm{dL}^{-1}(n=605)$ had a median BS of 10 (10-11) and $11(10-12)$, respectively. A median BS of $14(13-15)$ and 18 (15-21) was observed in patients with VWF:Act levels $\leq 10 \mathrm{IU} \mathrm{dL}^{-1}(n=186)$ or FVIII:C levels $\leq 10 \mathrm{IU} \mathrm{dL}^{-1}(n=33)$.

\section{Association between VWF and FVIII levels and CLT}

No associations were found between VWF or FVIII level and CLT, see Table 2. Patients in a subgroup with higher FVIII level (>30 IU dL ${ }^{-1}$ ) had slightly higher CLTs, although this difference was not statistically significant, $P$ for trend 0.097 . No associations were found between VWF or FVIII level and CLT ${ }^{+P C I}$, measuring CLT in the absence of TAFI activity, see Table 2. 


\begin{tabular}{lcrccc}
\hline & Levels* $^{*}$ & \multicolumn{1}{c}{ CLT $(\mathrm{IQR})$} & $P$ for trend & CLT $^{+ \text {PCI }}(\mathrm{IQR})$ & $P$ for trend $^{\dagger}$ \\
\hline VWF:Ag & $0-10$ & $100.3(90.4-112.5)$ & 0.122 & $72.5(65.6-79.1)$ & 0.222 \\
& $10-20$ & $99.5(90.8-109.7)$ & & $71.0(63.3-78.7)$ & \\
& $20-30$ & $101.5(91.0-114.2)$ & & $71.0(64.6-79.8)$ & \\
VWF:CB & $>30$ & $103.8(94.7-117.6)$ & & $73.3(66.3-82.8)$ & \\
& $0-10$ & $102.4(91.3-111.6)$ & 0.316 & $72.2(65.0-80.9)$ & 0.822 \\
& $10-20$ & $103.9(93.5-111.2)$ & & $72.4(67.2-79.7)$ & \\
VWF:Act & $20-30$ & $96.6(89.4-112.6)$ & & $71.0(64.4-78.5)$ & \\
& $>30$ & $103.0(93.6-117.7)$ & & $72.1(65.2-82.2)$ & \\
& $0-10$ & $100.4(90.3-110.5)$ & 0.121 & $71.0(64.9-78.5)$ & 0.421 \\
& $10-20$ & $103.2(91.8-110.6)$ & & $72.5(66.7-80.0)$ & \\
FVIII:C & $20-30$ & $103.5(92.9-115.5)$ & & $72.0(64.5-81.8)$ & \\
& $>30$ & $103.3(93.4-117.9)$ & & $72.6(65.9-82.8)$ & \\
& $0-10$ & $101.9(90.2-112.2)$ & 0.097 & $74.6(67.9-78.9)$ & 0.132 \\
& $10-20$ & $102.5(90.3-111.3)$ & & $71.7(65.4-78.4)$ & \\
& $20-30$ & $98.5(90.9-107.4)$ & & $68.7(64.9-78.7)$ & \\
& $>30$ & $103.4(92.9-115.0)$ & & $72.2(65.3-82.1)$ & \\
\hline
\end{tabular}

Table 2. Association between CLT and VWF/FVIII levels.

In $\mathrm{IU} \mathrm{dL}^{-1}$

${ }^{\dagger}$ Clot lysis time and clot lysis time ${ }^{+\mathrm{PCI}}$ were $10 \log$-transformed.

Table 3. Clot lysis time in subgroups of VWD patients.

\begin{tabular}{|c|c|c|c|c|c|c|c|c|}
\hline & & $N$ & Median CLT & IQR & ${ }^{*} P$-value & Median CLT $^{+ \text {PCI }}$ & IQR & " $P$-value \\
\hline \multicolumn{9}{|l|}{ Sex } \\
\hline \multirow[t]{2}{*}{ Children } & Boys & 35 & 90.8 & $85.3-98.0$ & 0.600 & 66.4 & $62.2-74.4$ & 0.771 \\
\hline & Girls & 26 & 90.4 & $84.8-103.0$ & & 68.4 & $60.4-74.1$ & \\
\hline \multirow[t]{2}{*}{ Adults } & Males & 214 & 106.2 & 95.7-118.1 & 0.008 & 71.7 & $65.7-81.5$ & 0.379 \\
\hline & Females & 363 & 101.9 & $92.8-114.0$ & & 72.8 & $66.6-81.8$ & \\
\hline \multirow[t]{3}{*}{ Age } & $0-16$ & 61 & 90.6 & $85.3-100.5$ & $<0.001$ & 67.5 & $61.0-74.1$ & $<0.001$ \\
\hline & $16-40$ & 200 & 99.4 & 90.9-108.5 & & 70.0 & $63.6-78.1$ & \\
\hline & $61-86$ & 133 & 107.0 & $99.0-117.3$ & & 75.4 & $68.4-83.7$ & \\
\hline \multirow[t]{3}{*}{ Type VWD } & Type 1 & 372 & 101.0 & $91.5-112.6$ & 0.259 & 70.4 & $63.9-78.9$ & $<0.001$ \\
\hline & Type 2 & 221 & 104.2 & $94.2-114.5$ & & 74.5 & $68.3-82.0$ & \\
\hline & Type 3 & 28 & 103.2 & $89.6-112.0$ & & 76.2 & $69.5-87.4$ & \\
\hline \multirow[t]{2}{*}{ Blood group } & $\mathrm{O}$ & 382 & 101.2 & 91.9-111.8 & 0.085 & 71.5 & $65.0-80.3$ & 0.100 \\
\hline & Non-O & 247 & 104.0 & $93.0-115.0$ & & 73.4 & $65.9-81.6$ & \\
\hline
\end{tabular}

IQR, interquartile range.

"Mann-Whitney $U$ or Kruskal-Wallis test for differences between subgroups.

Bold values indicate significant $P$-values.

\section{Determinants of CLT in VWD patients}

The CLTs were prolonged in men compared to women with VWD [106.2 (IQR 95.7-118.1) vs. 101.9 (IQR 92.8-114.0) min, $P=0.008$ ], see Table 3. In children no gender difference was found [90.8 (IQR 85.3-98.0) vs. 90.4 (IQR 84.8-103.0) $\mathrm{min}, P=0.600$ ], for boys and girls, respectively, see Fig. 3. The CLT steadily prolonged with age, an increase in age of 10 years was associated with an increase in CLT of $3.3 \mathrm{~min}$ (95\% CI 2.3-4.4). The CLTs of the children were significantly shorter compared with adult VWD patients [90.6 (IQR 85.3100.5 ) vs. 103.7 (IQR 93.2-115.0) $\mathrm{min}, P<0.001]$. No difference in CLT was found between patients with type 1,2 and 3 VWD. However, a significant difference in $\mathrm{CLT}^{+\mathrm{PCI}}$ (to exclude the effect of TAFI) between the various types of VWD was observed, see Table 3. Patients with type 3 VWD had prolonged CLTs compared with VWD type 1 and type 2 . Within the group of patients with type 2 VWD, patients with subtype $2 \mathrm{~A}$ had the highest CLT (data not shown).
Association between CLT measured in presence and absence of PCI

Correlation between CLT and CLT $^{+ \text {PCI }}$ was highly significant $(r=0.857, P<0.001)$, indicating that VWD patients with a high overall CLT also had a high basal, TAFI-independent CLT. To study the contribution of TAFI and TAFI activation on lysis time we measured CLT ratios. In Fig. 4, the CLT ratios per type of VWD are depicted. A significant higher CLT ratio was observed in type 1 compared to type 2 and type 3 VWD patients [median CLT ratio in type 1 VWD 1.45 (IQR 1.37-1.52), type 2 VWD 1.39 (IQR 1.32-1.47), type 3 VWD 1.36 (1.27-1.43), $P<0.001$ ].

\section{Effect of fibrinolysis on BS}

For both BS and BS-mucocutaneous three models were built to adjust for other factors that could potentially affect the association between BS and 


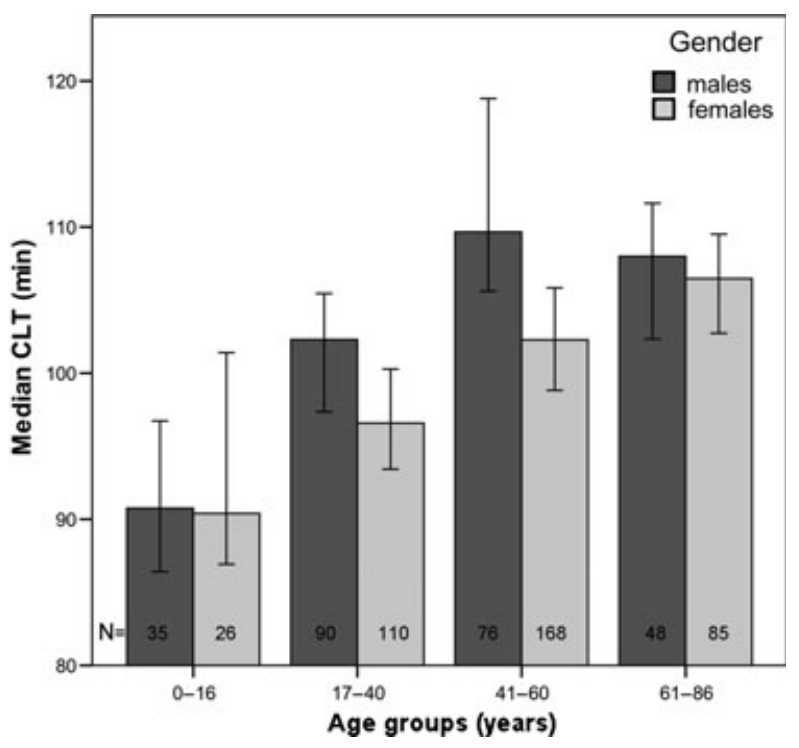

Fig. 3. Clot lysis time per gender and age-group. Children had significantly lower CLTs compared to all other age groups (Mann-Whitney test $P<0.001)$. Only in patients aged $41-60$ years a significantly different CLT was found between men and women (Mann-Whitney test $P=0.006$ ). Both for men and women CLTs increased significantly with age (Kruskal-Wallis test $P<0.001)$. Error bars: $95 \% \mathrm{CI}$.

CLT, including age, gender, VWF:Act and FVIII. The results are summarized in Table 4. An association was found between both BS and BS-mucocutaneous

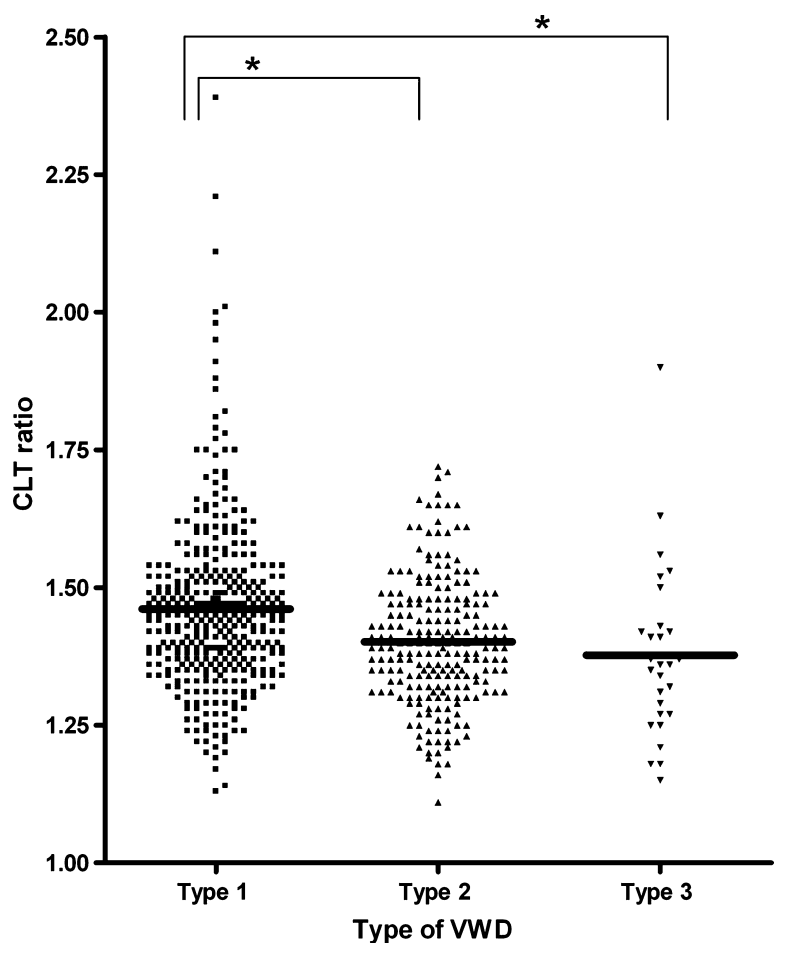

Fig. 4. Clot lysis time ratios in different types of VWD. CLT ratio is defined as CLT (with TAFI activity) divided by CLT ${ }^{+\mathrm{PCI}}$ (without TAFI activity). ${ }^{*} P<0.05$. Bars represent the median CLT:CLT ${ }^{+\mathrm{PCI}}$ ratio.
Table 4. Linear regression models representing the effect of clot lysis time on the Bleeding Score.

\begin{tabular}{|c|c|c|}
\hline & BS & BS mucocutaneous \\
\hline$n=638$ & $b(95 \% \mathrm{CI})$ & $b(95 \% \mathrm{CI})$ \\
\hline \multicolumn{3}{|l|}{ CLT } \\
\hline Model I & $9.6(2.8-16.4)$ & $7.9(3.3-12.4)$ \\
\hline Model II & $5.8(-1.2-12.8)$ & $5.4(0.7-10.1)$ \\
\hline Model III & $6.5(-0.3-13.4)$ & $5.3(0.7-10.0)$ \\
\hline
\end{tabular}

Model I: independent variable $10 \log$-CLTs.

Model II: independent variables $10 \log$-CLTs, age and gender.

Model III: independent variables 10log-CLTs, age, gender, VWF:Act and FVIII.

b represents the increase in BS or BS mucocutaneous per min increase of 10log-CLT.

with 10log-transformed CLT $[b=9.6$ (95\% CI $2.8-$ 16.4), and $b=7.9$ (95\% CI 3.3-12.4), respectively]. However, for BS and CLT no significant association was found after adjustment for age, gender, VWF:Act and FVIII $(b=6.5,95 \% \mathrm{CI}-0.3$ to 13.4$)$, for BS-mucocutaneous a small regression coefficient was found $(b=5.3,95 \%$ CI $0.72-10.0)$. After additional stratification for type of VWD this association disappeared (data not shown).

\section{Discussion}

We did not observe an association between the fibrinolytic potential, measured by a plasma-based clot lysis assay, and bleeding tendency in our cohort of moderate to severe VWD patients. Therefore, our hypothesis that a higher fibrinolytic potential may increase the bleeding tendency in VWD patients could not be confirmed in this study.

In patients with VWD, a large variation in fibrinolytic capacity was observed, which was irrespective of FVIII and VWF level. The fibrinolysis assay we used is an overall measure of the plasma fibrinolytic potential in which the total balance of plasma proteins involved in clot degradation determines the outcome, and a single factor is only of limited importance [7]. The large variability in CLT was also observed earlier in healthy individuals $[6,16,17]$.

We hypothesized that enhanced fibrinolysis might result in a more severe bleeding tendency, leading to an inverse relationship between CLT and bleeding phenotype, assessed by the Tosetto Bleeding Score. We studied mucocutaneous bleeding separately, because of the high fibrinolytic activity in mucosal tissue and the high frequency of mucosal bleeding in patients with fibrinolysis abnormalities [20]. We found a weak, positive association between CLT and BS, however, in adjusted models this association disappeared. This is in line with a previous study in haemophilia patients, in whom an association between clot lysis and bleeding phenotype could not be demonstrated [21].

An explanation for the fact that no association between BS and CLT was found, might be that our 
cohort was strictly defined and only patients with moderate or severe VWD i.e those who have a relatively high BS were included. The selection of the study-group, not including mild VWD patients may have masked the effect of fibrinolysis on bleeding tendency. Mild VWD patients have a larger variability in bleeding phenotype and may be better suited to study the effect of fibrinolysis on bleeding variability. Furthermore, we studied bleeding phenotype by determining the BS in our study [3]. We used the BS because it is a validated method to determine bleeding phenotype in VWD patients. The BS was originally developed by Tosetto et al. to distinguish between type 1 VWD patients and patients without VWD. This BS has not been used to quantify bleeding symptoms in patients with disorders of fibrinolysis.

The CLT was also measured in presence of PCI, an inhibitor of activated TAFI, to study specifically the role of TAFI. We hypothesized that very low FVIII levels in severe VWD patients might influence the fibrinolytic system because of less TAFI activation, which may in turn lead to differences in bleeding phenotype. The fibrinolytic potential measured in the presence of TAFI inhibitor $\left(\mathrm{CLT}^{+\mathrm{PCI}}\right)$ was indeed increased (shortened $\mathrm{CLT}^{+\mathrm{PCI}}$ ). The anticipated effect of low FVIII activity and concomitant reduced TAFI activation on CLT is not reflected in the clot lysis assay in our study (Table 2). Previous studies showed that FVIII levels were not associated with CLTs in healthy individuals [7]. Furthermore, it was shown that addition of only $0.01 \mathrm{U} \mathrm{dL}^{-1}$ FVIII in severe haemophilia A patients, who are completely lacking FVIII, already resulted in maximal prolongation of CLT, suggesting the effect of FVIII at fibrinolysis is maximal at low concentration [22].

Although we did not find an association between the global plasma fibrinolysis and bleeding tendency, future studies should investigate whether or not the variation in bleeding tendency in VWD might be partly related to individual components of the fibrinolytic system. In the global fibrinolysis assay that we used in this study, exogenous t-PA was added, therefore effects of t-PA or other fibrinolysis protein variations might be masked. Other global fibrinolysis assays or measurement of individual fibrinolysis proteins including $\alpha_{2}$-antiplasmin, PAI-1 or TAFI levels may still be relevant in understanding the variation in bleeding tendency in VWD.
In conclusion, our study showed that the plasma fibrinolytic potential does not influence bleeding tendency in VWD patients and therefore does not explain the variability in bleeding phenotype in VWD.

\section{Acknowledgements}

The WiN study was supported by research funding from Dutch Hemophilia Foundation (Stichting Hemophilia) and CSL Behring (unrestricted grant). We thank all participating haemophilia patients and all nurses for their work on including patients. We thank Jacqueline de Klerk and Joyce Malfliet for the laboratory measurements.

\section{Author contributions}

FWGL and DR designed the research, analysed and interpreted data, and wrote the manuscript. EMW and KK performed research, analysed and interpreted data, and wrote the manuscript. EPMB, JGB, JCJE, KF, AGB and BLG: designed research, analysed and interpreted data, and critically reviewed the manuscript. MDD: analysed and interpreted data, and critically reviewed the manuscript. All authors gave their consent to the final version of the manuscript.

\section{Disclosures}

FWGL is a member of the Dutch haemophilia advisory board of CSL Behring, and attended a round table meeting of Baxter. HCJE received research support from CSL Behring and he has been a teacher on educational activities of Roche. KM and EPMB are members of the Dutch haemophilia advisory board of CSL Behring. J.G. van der Bom has received unrestricted research/educational funding for various projects from the following companies: Bayer Schering Pharma, Baxter, CSL Behring, Novo Nordisk, and Wyeth. In addition, she has been a consultant to Baxter and Wyeth, and she has been a teacher on educational activities of Bayer Schering Pharma. None of the other authors has a conflict of interest to declare.

\section{Appendix: WiN study group}

Academic Medical Center, Amsterdam: K. Fijnvandraat, P.W. Kamphuisen; VU University Medical Center, Amsterdam: A. Kors, S. Zweegman; Netherlands Hemophilia Society, Badhoevedorp: M.E.L. Degenaar-Dujardin; Amphia hospital, Breda: G.J. Goverde, M.H. Jonkers; Catharina hospital, Eindhoven: N. Dors, W.J.D. Hofhuis; Maxima Medical Center, Eindhoven: M.R. Nijziel; University Medical Center Groningen, Groningen: K. Meijer, R.Y.J. Tamminga; Kennemer Gasthuis, Haarlem: P.W. van der Linden; HagaZiekenhuis, The Hague: P.F. Ypma; Leiden University Medical Center, Leiden: J.G. van der Bom, H.C.J. Eikenboom, F.J.W. Smiers; Maastricht University Medical Center, Maastricht: B. Granzen, K. Hamulyák; Radboud University Nijmegen Medical Centre, Nijmegen: P. Brons, B.A.P. Laros-van Gorkom, I. Nováková Erasmus University Medical Center, Rotterdam: A. de Goede-Bolder, F.W.G. Leebeek (principal investigator), E.M. de Wee; Van Creveldkliniek and hematology, University Medical Center, Utrecht: E.P. Mauser-Bunschoten (chair steering committee).

\section{References}

1 Sadler JE, Mannucci PM, Berntorp E et al. Impact, diagnosis and treatment of von Willebrand disease. Thromb Haemost 2000; 84: 160-74.

2 Ruggeri ZM. Structure of von Willebrand factor and its function in platelet adhesion and thrombus formation. Best Pract Res Clin Haematol 2001; 14: 257-79.
3 Tosetto A, Rodeghiero F, Castaman G et al. A quantitative analysis of bleeding symptoms in type 1 von Willebrand disease: results from a multicenter European study (MCMDM-1 VWD). J Thromb Haemost 2006; 4: 766-73.

4 Rugeri L, Beguin S, Hemker C et al. Thrombin-generating capacity in patients with von Willebrand's disease. Haematologica 2007; 92: 1639-46.
5 Rijken DC, Lijnen HR. New insights into the molecular mechanisms of the fibrinolytic system. J Thromb Haemost 2009; 7: 413.

6 Mosnier LO, von dem Borne PA, Meijers JC, Bouma BN. Plasma TAFI levels influence the clot lysis time in healthy individuals in the presence of an intact intrinsic pathway of coagulation. Thromb Haemost 1998; 80: 829-35. 
7 Lisman T, de Groot PG, Meijers JC, Rosendaal FR. Reduced plasma fibrinolytic potential is a risk factor for venous thrombosis. Blood 2005; 105: 1102-5.

8 Meltzer ME, Lisman T, de Groot PG et al. Venous thrombosis risk associated with plasma hypofibrinolysis is explained by elevated plasma levels of TAFI and PAI-1. Blood 2010; 116: 113-21.

9 Carpenter SL, Mathew P. Alpha2-antiplasmin and its deficiency: fibrinolysis out of balance. Haemophilia 2008; 14: 1250-4.

10 Mehta R, Shapiro AD. Plasminogen activator inhibitor type 1 deficiency. Haemophilia 2008; 14: 1255-60.

11 Leebeek FW, Stibbe J, Knot EA, Kluft C, Gomes MJ, Beudeker M. Mild haemostatic problems associated with congenital heterozygous alpha 2-antiplasmin deficiency. Thromb Haemost 1988; 59: 96-100.

12 Silwer J. von Willebrand's disease in Sweden. Acta paediatrica Scandinavica 1973, 238: 1-159.

13 Sadler JE, Budde U, Eikenboom JC et al. Update on the pathophysiology and classification of von Willebrand disease: a report of the Subcommittee on von Willebrand Factor. I Thromb Haemost 2006; 4: 2103-14.

14 Nichols WL, Hultin MB, James AH et al. von Willebrand disease (VWD): evidencebased diagnosis and management guidelines, the National Heart, Lung, and Blood Institute (NHLBI) Expert Panel report (USA). Haemophilia 2008; 14: 171-232.

15 Federici AB. Clinical diagnosis of von Willebrand disease. Haemophilia 2004; 10(Suppl. 4): 169-76.

16 Guimaraes AH, de Bruijne EL, Lisman T et al. Hypofibrinolysis is a risk factor for arterial thrombosis at young age. $\mathrm{Br} J \mathrm{Hae}$ matol 2009; 145: 115-20.

17 Hoekstra J, Guimaraes AH, Leebeek FW et al. Impaired fibrinolysis as a risk factor for Budd-Chiari syndrome. Blood 2010; 115: 388-95.

18 Leebeek FW, Goor MP, Guimaraes AH et al. High functional levels of thrombinactivatable fibrinolysis inhibitor are associ- ated with an increased risk of first ischemic stroke. J Thromb Haemost 2005; 3: 2211-8.

19 Bowman M, Riddel J, Rand ML, Tosetto A, Silva M, James PD. Evaluation of the diagnostic utility for von Willebrand disease of a pediatric bleeding questionnaire. I Thromb Haemost 2009; 7: 1418-21.

20 Agren A, Wiman B, Stiller V et al. Evaluation of low PAI-1 activity as a risk factor for hemorrhagic diathesis. J Thromb Haemost 2006; 4: 201-8.

21 van Dijk K, van der Bom JG, Fischer K, de Groot PG, van den Berg HM. Phenotype of severe hemophilia A and plasma levels of risk factors for thrombosis. I Thromb Haemost 2007; 5: 1062-4.

22 Mosnier LO, Lisman T, van den Berg HM, Nieuwenhuis HK, Meijers JC, Bouma BN. The defective down regulation of fibrinolysis in haemophilia A can be restored by increasing the TAFI plasma concentration. Thromb Haemost 2001; 86: 1035-9. 